\title{
Molecular characterization of Mycobacterium avium subsp. paratuberculosis (MAP) in dairy cattle of Nepal
}

\author{
S. Singh ${ }^{1^{*}}$, I. P. Dhakal ${ }^{1}$, U. M. Singh ${ }^{2}$ and B. Devkota ${ }^{1}$ \\ ${ }^{1}$ Agriculture and Forestry Univers ity, Rampur, Chitwan, Nepal. \\ ${ }^{2} \mathrm{Nepal}$ Agriculture Research Council, Kathmandu, Nepal. \\ "Corresponding author. Email: ssingh@afu.edu.np
}

Copyright @ 2020 Singh et al. This article remains permanently open access under the terms of the Creative Commons Attribution License 4.0, which permits unrestricted use, distribution, and reproduction in any medium, provided the original work is properly cited.

Received 25th November, 2020; Accepted 16th December, 2020

\begin{abstract}
Paratuberculosis caused by Mycobacterium avium subspecies paratuberculosis (MAP), is an economically important, endemic in many parts of the globe, and regarded as high prevalent disease of domestic and wild animals, especially ruminants, which is manifest as chronic granulomatous enteritis with decreased milk production, with serious cases resulting in progressive emaciation and death. Understanding the genetic variability of MAP, strains are important in diagnosis, epidemiological investigation, and therefore the formation of strategies for prevention and control of the disease. Thus, this study was designed to grasp the molecular characterization of MAP isolates of Nepal, as pioneer research of this area. Total of 46 MAP isolates obtained from cattle population of three different locations of dairy pocket areas of Chitwan, Nepal were typed using IS1311 polymerase chain reaction-restriction endonuclease analysis (PCRREA) to research the MAP genotype of Nepal. The extracted DNA samples $(n=46)$ were analyzed for the presence of MAP specific sequences (IS900) using PCR and DNA samples were further subjected to genotype differentiation using IS 1311 PCR-REA and IS 1311 L2 PCR-REA methods. All the DNA samples were positive for the entire three MAP specific sequences based PCRs. This study revealed that 'Bison type' strain is the single most prevalent MAP genotype circulating within the domestic cattle population of Nepal. IS 1311 PCR-REA showed that MAP DNA samples of Nepal origin belonged to 'Bison type', whereas, IS 1311 L2 PCR-REA method showed similarity with "Indian Bison type" and different restriction profiles of 'Bison type' genotype as compared to non-Indian strains. The study concludes that in Nepal, "Bison type" MAP stains was prevalent in all the MAP samples obtained from dairy cattle. These results have important epidemiological implications regarding control and prevention of paratuberculosis in Nepal.
\end{abstract}

Keywords: Bison type, IS 1311PCR-REA, MAP, molecular characterization, Nepal.

\section{INTRODUCTION}

Paratuberculosis, also known as Johne's disease (JD), caused by Mycobacterium avium subspecies paratuberculosis (MAP), is an economically important, endemic in many parts of the world including Nepal, and considered as highly prevalent disease of domestic and wild ruminants, manifest as a chronic granulomatous enteritis with decreased milk production, and in more serious cases leading to progressive emaciation and death (Yue et al., 2016). MAP is a fastidious, slow growing acidfast organism (Behr and Kapur, 2008). Clinical symptoms of paratuberculosis include slowly progressive wasting and chronic or intermittent, therapy-resistant diarrhoea (Stabel, 1997), which are intermittent initially, but become progressively more severe until they are constantly present. Affected animals become increasingly emaciated and typically die as a result of dehydration and severe cachexia (Cheng et al., 2020).

Johne's disease causes high impact on livestock industry, because of premature culling of animals, reduced weight gain, reduced feed efficiency, high morbidity (Kaur 
et al., 2011), poor carcass quality, reduced milk yield, increased disease susceptibility to mastitis and reproductive disorders leading to increased calving intervals, poor fertility and additional veterinary costs (Hasonova and Pavlik, 2006). With the recent study, the prevalence of MAP in dairy cattle of Nepal was detected as $16.59 \%$ by faecal PCR in Nepal (Singh et al., 2020). Paratuberculosis is chargeable for considerable economic losses causing disease within the dairy industry within the U.S., estimated about over $\$ 200$ million each year (Groenendaal et al., 2015), and thus draws significant attention in developing as well as well developed countries. No country claims that it is free on MAP (Yue et al., 2016). The disease is taken into account one amongst the foremost important diseases of ruminant population (Sivakumar et al., 2005), however, MAP has also been isolated from a large range of non-ruminant including horses, pigs, rabbits, foxes, stoats, weasels (Beard et al., 2001), humans (Chiodini et al., 1984) and non-human primates (McClure et al., 1987). Paratuberculosis is similar to Crohn's disease in humans (McAloon et al., 2019), which reflects that MAP is potential etiology of Crohn's disease (Sechi and Dow, 2015), and thus, has amplified the possible zoonotic threat.

Control of MAP infection is the priority of developed countries to secure animal productivity and to cut back chances of human exposure. Vaccination is considered as the reliable method of choice for the control of JD in animals, however, efficacy of vaccines depends on the genotype of candidate strain used (Singh et al., 2007). According to Sonawane et al. (2015), the genetic variability of various MAP strains and their impact on infection and pathogenesis has significant implication for diagnosis and control of JD. Therefore, better understanding of the genotypes infecting livestock species is analytical for designing disease control strategies. Based on IS1311 polymerase chain reaction restriction endonuclease analysis (PCR-REA) method, MAP isolates are grouped into three genetically distinct genotypes, namely, 'Cattle type', 'Sheep type' and 'Bison type (Sevilla et al., 2005).

Several researches have identified genomic variations in terms of genetic rearrangements, in-del polymorphisms and locus polymorphisms in 'Bison type' genotype of Indian origin in comparison with genotypes reported from other parts of the world, and thus, new nomenclature 'Indian Bison type' was assigned to 'native Bison type' genotype (Sohal et al., 2010). As contrast, molecular signature (sequence variations of native genotype) was deletion of two base pairs (TG) at $64^{\text {th }}$ and $65^{\text {th }}$ positions of IS 1311 element particularly at locus 2 as compared to nonIndian isolates (Sohal et al., 2010) and with advantage of this molecular signature, a brand new IS1311 locus 2 specific PCR-REA (IS1311 L2 PCR-REA) assay was optimized for discrimination of 'Indian Bison type' from other isolates (Sohal et al., 2013).

Thus, this present study was decerned to analyze molecular characterization of MAP isolates obtained from different locations of dairy pocket areas of Chitwan, Nepal.

\section{MATERIALS AND METHODS}

\section{Sample and sampling}

Samples were collected from three major dairy pocket areas namely, Ratnanagar, Gitanagar and Mangalpur of Chitwan district, Bagmati province, Nepal. The cattle herds were selected on random base and sampling were done from individual lactating cows old $\geq 2$ years showing diarrhea and poor body score (purposive sampling) with suspect of the disease. The faecal samples were kept at $4^{\circ} \mathrm{C}$ until they were transported to the laboratory and stored up to 48 hours before further processing.

\section{Bacterial isolates, DNA extraction and IS900 PCR}

Fecal cultures of the samples were done under protocol as recommended by Ristow et al. (2006) and DNA extraction from MAP colonies was done as stated by van Soolingen et al. (1993). Later, PCR using specific IS900 commercial PCR test primer was performed for confirmation of DNA samples and standardization. The use of IS900 in this type of PCR is sensitive to reveal very low numbers of MAP, but insufficient for accurate quantification of CFU within the sample, since its present in many copies within the bacterial genome (Singh et al., 2018).

\section{Molecular characterization of MAP by IS1311 PCR- REA}

A total of 46 MAP isolates (harvested by fecal culture and later confirmed by IS900 gene PCR) of various locations were processed for the investigation of molecular genotyping (molecular characterization) using IS1311 PCR-REA and IS 1311 L2 PCR-REA. Out of the 46 MAP isolates, 16, 15 and 15 were from Ratnanagar, Geetanagar and Mangalpur, respectively, of Bagmati Province, Central Plain region of Nepal. Similarly, to examine the specificity of IS1311 L2 PCR-REA, a set of five mycobacterial isolates aside from MAP [M. marinum, M. fortuitum, M. kansasii, M. bovis, $M$. bovis (BCG)] were used for this research. All the mycobacterial isolates were subjected to isolation of genomic DNA as per the method designed by van Soolingen et al. (1993). DNA samples recovered from isolates samples were subjected to IS900 (Singh et al., 2020) specific PCRs for the molecular identification of MAP.

\section{IS1311PCR-REA (Genotyping of isolates)}

Genotyping of every MAP DNA obtained from mycobacterial isolates was allotted by IS1311 PCR-REA 
method (Sevillaet al., 2005). In brief, the reaction was distributed in $30 \mu \mathrm{l}$ volume, containing $20 \mu \mathrm{l}$ positive IS 1311 PCR product, $3 \mu$ 10X buffer (Fermentas, USA), 2 units of every endonuclease Hinfl and Msel (Fermentas). Reaction mixture was incubated at $37^{\circ} \mathrm{C}$ for 1.5 hours. Band patterns were visualized after electrophoresis on four percent high resolution agarose gel stained with ethidium bromide and genotype profile analysis was done as described by Sevilla et al. (2005).

\section{IS1311locus 2 PCR-REA (Sub-genotyping of MAP isolates)}

IS 1311 L2 PCR-REA was used to specify all MAP isolates DNA included during this study. Initially, locus 2 of IS 1311 was amplified using the distinct primers (P1: CACCAACCATGCAGAGGTAA; P2: GGAATCCGCAACTCCAAAT) and then amplicons were subjected to restriction digestion using BsaJ1. PCR reaction mix contained primers $(10$ pmoles $)$, Taq polymerase (1 unit), $\mathrm{MgCl}_{2}(1.5 \mathrm{mM})$, dNTPs $(0.2 \mathrm{mM})$, buffer 10X $(2.5 \mu \mathrm{l})$ and template DNA $(5 \mathrm{ng})$ during a final volume of $25.0 \mu \mathrm{l}$ at thermocycler conditions: denaturation at $95^{\circ} \mathrm{C}$ for five minutes followed by 40 cycles of denaturation at $95^{\circ} \mathrm{C}$ for 30 seconds, annealing at $55^{\circ} \mathrm{C}$ for 30 seconds, extension at $72^{\circ} \mathrm{C}$ for 1 minute, followed final extension at $72^{\circ} \mathrm{C}$ for 7 minutes. PCR products were visualized on 1.5 percent agarose gel. Amplification products ( 425 bp) were digested with BsaJl enzyme for two hours at $37^{\circ} \mathrm{C}$ and band pattern was detected on four percent agarose gel.

\section{RESULTS}

\section{Molecular detection of MAP isolates by using PCR targeting IS 900 sequence}

All the samples were tested by IS900 PCR before proceeding to Polymerase Chain Reaction - Restriction Endonuclease Analysis (PCR-REA). MAP specific IS900 PCR showed presence of MAP DNA in all 46 DNA isolates (samples) as shown in Figure 1, except those extracted from isolates of mycobacteria other than MAP. The reference MAP strains K-10 and ATCC19698 were found positive by PCR method.

\section{Molecular typing of MAP by IS1311 PCR-REA and IS 1311 L2 PCR-REA}

\section{IS1311 PCR-REA (Genotyping)}

All 46 MAP DNA samples showed the pattern of 'Bison type' genotype (Figure 2). Thus, it was confirmed that all MAP DNA samples of three different regions of Nepal belonged to 'Bison type'.

\section{IS1311 L2 PCR-REA (Sub-genotyping)}

Restriction profile and band pattern for marker IS 1311 L2 PCR REA results similar with genotype of 'Indian Bison type' MAP from all the samples (Figure 3). After restriction digestion of $\sim 425$ bp product (belonging to IS 1311 element at locus 2) with BsaJl enzyme, four digestion products were visualized in the 4 percent high resolution agarose gel $(34,67,78$ and $230 \mathrm{bp})$ for other MAP isolates. However, digestion of IS 1311 locus 2 amplicon of MAP DNA of Indian origin resulted into only three detectable bands in the gel (67, 78 and 262 bp).

\section{DISCUSSION}

The molecular epidemiology of MAP has been neglected to investigate due to slow growing nature of bacteria in artificial medium. Thus, rapid strain differentiation methods are important to understand the origin of infection, disease transmission and to design disease control strategies. In the present study, IS1311 PCR-REA method was applied on MAP isolates from different dairy pocket areas of Nepal and MAP positive faecal DNA samples for determining their genotype. DNA based studies using 'Restriction Fragment Length Polymorphism (RFLP)' of genomic DNA from MAP isolates from a range of hosts confirmed the existence of two strains referred to as either sheep (S type) or cattle (C type) (Whittington and Sergeant, 2001), and one MAP strain referred to as bison (B type) (Sevilla et al., 2005). According to Thibault et al. (2012), it was found that the "Indian Bison type" strains were a sublineage of Type C strains.

All DNA samples obtained from MAP infected animals of Nepal were genotyped as 'Bison type' which is the first report to identify the strain of MAP present in Nepal. In present study, no 'Cattle type' and 'Sheep type' genotype of MAP in animals were detected. These results suggested that in Nepal, "Bison type" strains might be circulating among the cattle population, which is quite interesting, given that bison strains have been reported only in bison from USA (Sonawane et al., 2015). These findings were similar to that reported in previous epidemiological investigations conducted in north India (Singh et al., 2009). Contrary to the present finding, 'Bison type' was found to be the foremost prevalent MAP genotype whereas "Cattle type" was present in minority of cases from cattle, buffalo, and goats of India (Kaur et al., 2010). Likewise, studied done in India revealed that 'Cattle type' genotype of MAP was found as predominant genotype infecting domestic livestock, wild ruminant and non-ruminant species in other countries (Motiwala et al, 2006). 'Sheep type' strains are rarely associated with paratuberculosis in species other than sheep (Sevilla et al., 2007).

The results showed that new IS1311 L2 PCR-REA assay successfully discriminated genotype exactly similar 


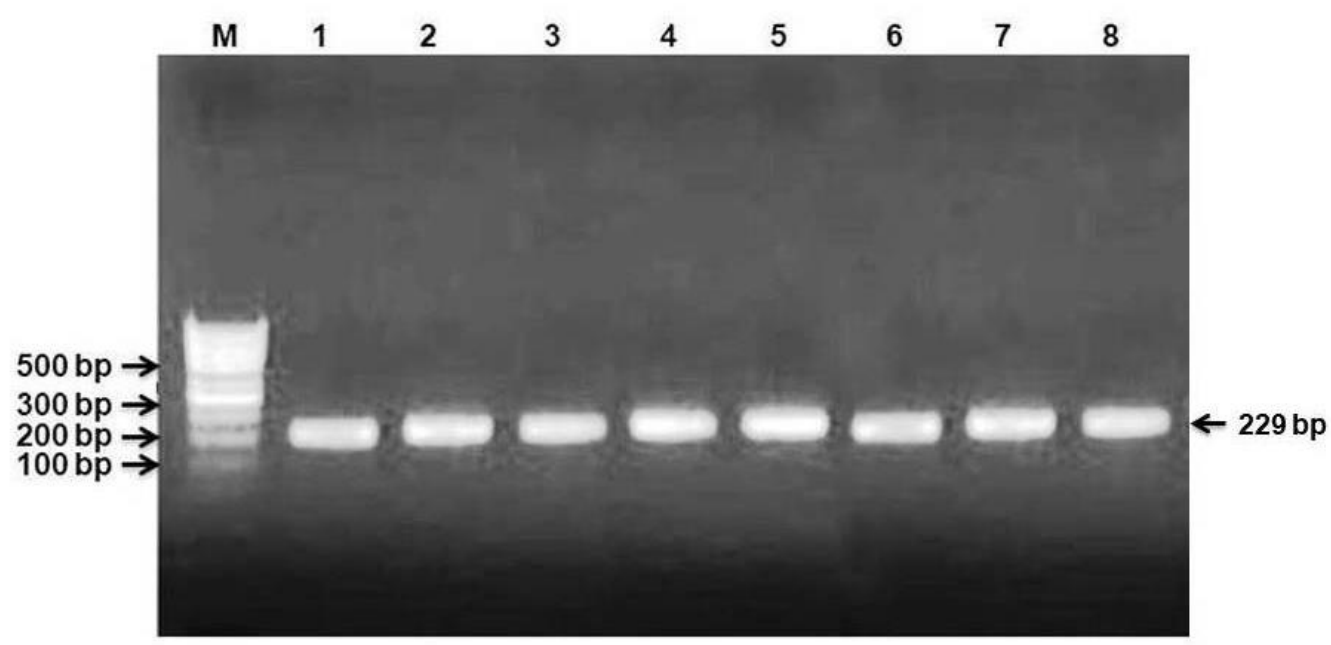

Figure 1. Molecular detection of MAP isolates by using PCR targeting IS900 sequence (specific product size $229 \mathrm{bp}$ ). Lane M: 100 bp marker; Lane 1: Positive Control (Indian Bison type MAP S5); Lane 2: Sample no. R09 (MAP positive); Lane 3: Sample no. R13 (MAP positive); Lane 4: Sample no. R16 (MAP positive); Lane 5: Sample no. G06 (MAP positive); Lane 6: Sample no. G10 (MAP positive); Lane 7: Sample no. M03 (MAP positive); Lane 8: Sample no. M07 (MAP positive).

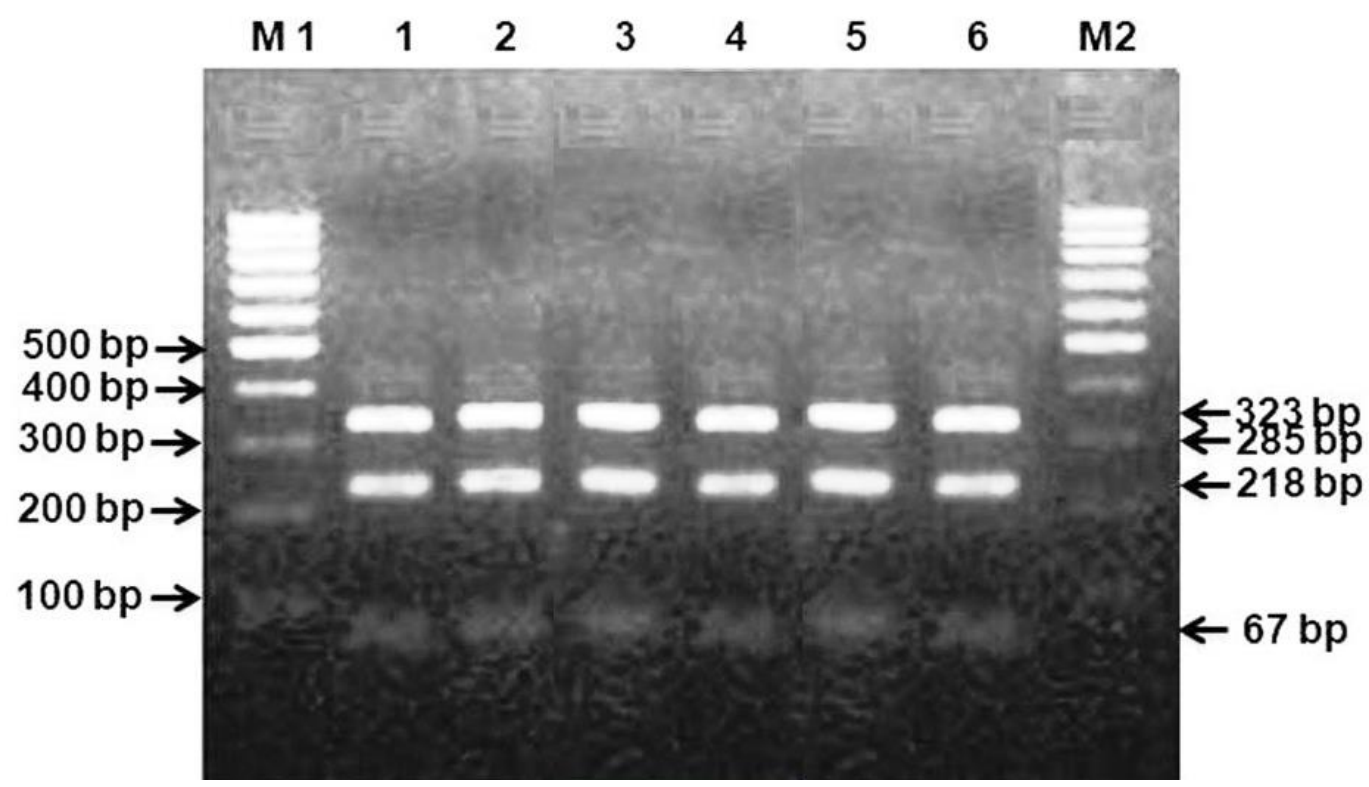

Figure 2. Genotyping of MAP isolates by using IS 1311 PCR-restriction endonuclease analysis. Lane M1: 100 bp marker; Lane 1: Isolate no. R07 (Bison type MAP positive); Lane 2: Isolate no. R11 (Bison type MAP positive); Lane 3: Isolate no. G06 (Bison type MAP positive); Lane 4: Isolate no. G09 (Bison type MAP positive); Lane 5: Isolate no. M07 (Bison type MAP positive); Lane 6: Isolate no. M11 (Bison type MAP positive); Lane M2: 100 bp DNA ladder/marker.

to 'Bison type' genotype of Indian origin ('Indian Bison type') from MAP isolates of other genotypes (Cattle type, Sheep type and Bison type). The test was found to be very specific as all mycobacterial isolates (except $M$. avium) apart from MAP could not be amplified by the MAP specific primers. Due to high genetic similarity between $M$. avium and MAP, IS1311 L2 PCR amplified the DNA of both. However, the restriction profiles of IS 1311 locus 2 by BsaJ1 restriction enzyme were different among both species. This study confirmed that 'TG' gap deletion at $64^{\text {th }}$ 


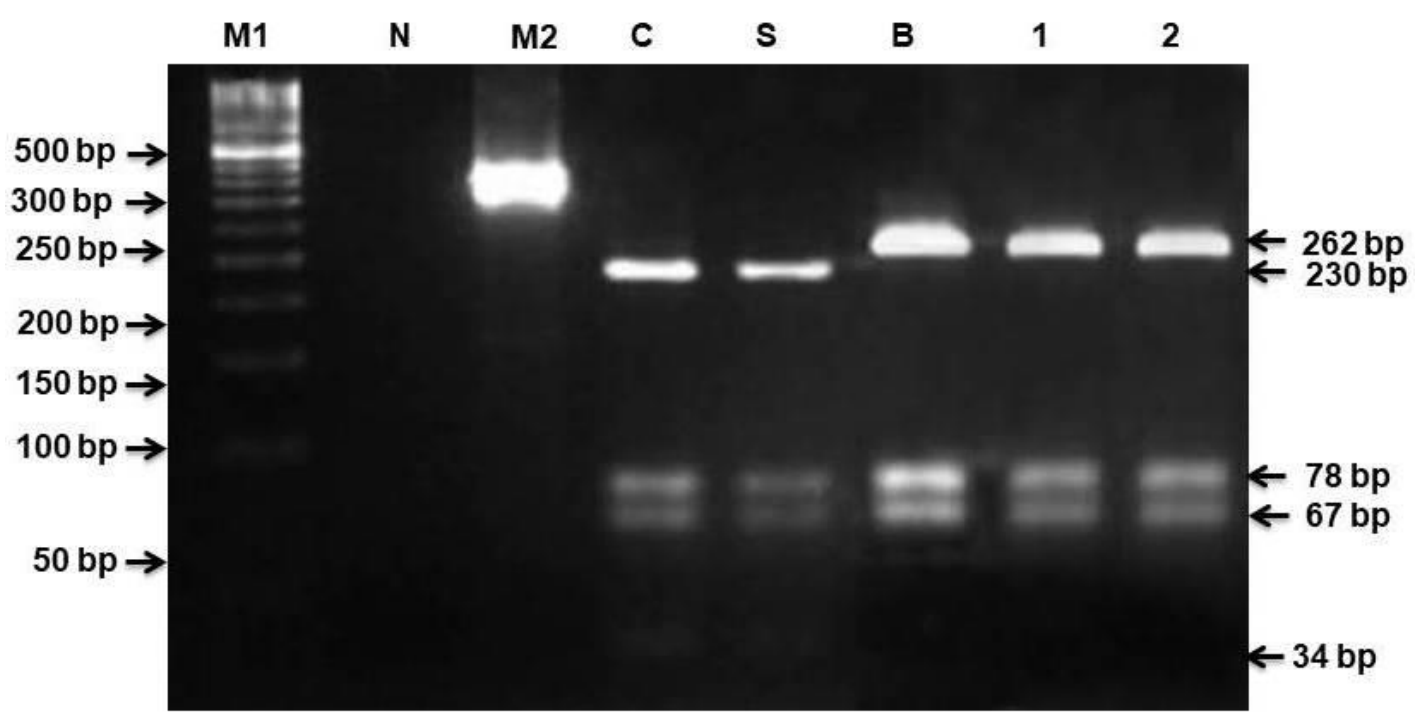

Figure 3. Discriminatory restriction pattern of typical MAP isolates using IS 1311 PCR locus 2-REA method. Lane M1: Marker (50bp); Lane N: Negative control, Lane M2: Undigested PCR product ( 425bp); Lane C: Cattle type MAP positive; Lane S: Sheep type MAP positive; Lane B: Bison type MAP positive); Lane 1: Isolates no. R16 ('Bison' type Indian origin MAP positive); Lane 2: Isolates no. M09 ('Bison' type Indian origin MAP positive). Note: MAP = Mycobacterium avium subspecies paratuberculosis; $\mathrm{PCR}=$ polymerase chain reaction; REA = restriction endonuclease analysis .

and $65^{\text {th }}$ position of IS 1311 element at locus 2 was a stable marker and could be used in future strain typing as 'Molecular signature' and in epidemiological investigations (Singh et al., 2015).

This study confirms that MAP strains "Bison type" found in Nepal has similarity exactly with the "Indian Bison type" but different with other strains. This fact has significant epidemiological implications and support the scientific aspects that diagnostics and vaccines prepared from foreign MAP isolates might not be very effective, except vaccine prepared from "Indian Bison type" strain.

In this study, only 46 isolates obtained from dairy cattle of three locations from Chitwan districts were considered, however, large numbers of isolates from different ruminant species and geographic regions have to be characterized so as to assess a national scenario about the foremost prevalent MAP genotype in Nepal.

\section{Conclusion}

Based on PCR-REA patterns of the MAP isolated obtained from dairy cattle of various locations of Nepal, it could be concluded that the "Bison type MAP strain" was the sole circulating strain, which has important epidemiological implications in controlling paratuberculosis in Nepal. The current study validates that IS 1311 L2 PCR-REA assay is a rapid and simple method for the differentiation of 'Bison type' MAP isolates of Indian origin from non-Indian MAP isolates of various genotypes. MAP is an important livestock pathogen world over, which besides inviting trade restrictions, may be a potential human pathogen.

\section{CONFLICT OF INTEREST}

The authors declare that they have no conflict of interest.

\section{ACKNOWLEDGEMENTS}

The authors acknowledge National Institute of Animal Health, Japan for providing DNA of the standard MAP strains. The authors are thankful to IVRI, Izatnagar, Barely, India for laboratory facilities. Similarly, the authors would like to extend high appreciation to senior scientists Dr. S.V. Singh and his team of CIRG, Makhdoom, Mathura, India for laboratory technology/facilities and scientific knowledge sharing.

\section{REFERENCES}

Beard, P. M., Daniels, M. J., Henderson, D., Pirie, A., Rudge, K., Buxton, D., Rhind, S., Greig, A., Hutchings, M., \& McKendrick, I. (2001). Paratuberculosis infection of non-ruminant wildlife in Scotland. Journal of Clinical Microbiology, 39(4), 1517-1521.

Behr, M. A., \& Kapur, V. (2008). The evidence for Mycobacterium paratuberculosis in Crohn's disease. Current Opinion in Gastroenterology, 24(1), 17-21.

Cheng, Z., Liu, M., Wang, P., Peng, Liu, P., Chen, M., Zhang, J., Liu, S., \& Wang, F. (2020). Characteristics and Epidemiological Investigation of Paratuberculosis in Dairy Cattle in Taian, China. BioMed Research International, Volume 2020, Article ID 3896754.

Chiodini, R. J., Van Kruiningen, H. J., Merkal, R.S., Thayer, W. R., \& Coutu, J. A. (1984). Characteristics of an unclassified Mycobacterium species isolated from patients with Crohn's 
disease. Journal of Clinical Microbiology, 20(5), 966-971.

Groenendaal, H., Zagmutt, F. J., Patton, E. A., \& Wells, S. J. (2015). Cost-benefit analysis of vaccination against Mycobacterium avium subsp. paratuberculosis in dairy cattle, given its cross-reactivity with tuberculosis tests. Journal of Dairy Science, 98(9), 6070-6084.

Hasonova, L., \& Pavlik, I. (2006). Economic impact of paratuberculosis in dairy cattle herds: A review. Veterinarni Medicina, 51(5), 193-211.

Kaur, P., Filia, G., Singh, S. V., Patil, P. K., \& Sandhu, K. S. (2010). Molecular detection and typing of Mycobacterium avium subspecies paratuberculosis from milk samples of dairy animals. Tropical Animal Health and Production, 42(5), 10311035.

Kaur, P., Filia, G., Singh, S. V., Patil, P. K., Ravi Kumar, G. V. P. P. S., \& Sandhu, K. S. (2011). Molecular epidemiology of Mycobacterium avium subspecies paratuberculosis: IS900PCR identification and IS 1311 polymorphism analysis from ruminants in the Punjab region of India. Comparative Immunology, Microbiology and Infectious Diseases, 34(2), 163-169.

McAloon, C. G., Roche, S., Ritter, C., Barkema, H. W., Whyte, P., More, S. J., \& Doherty, M. L. (2019). A review of paratuberculosis in dairy herds - Part 2: On-farm control. The Veterinary Journal, 246, 54-58.

McClure, H. M., Chiodini, R. J., Anderson, D. C., Swenson, R. B., Thayer, W. R., \& Coutu, J. A. (1987). Mycobacterium paratuberculosis infection in a colony of stump-tail macaques (Macacaarctoides). Journal of Infectious Diseases, 155(5), 1011-1019.

Motiwala, A. S., Li, L., Kapur, V., \& Sreevatsan, S. (2006). Current understanding of the genetic diversity of Mycobacterium avium subsp. paratuberculosis. Microbes Infect and Infection, 8(5), 1406-1418.

Ristow, P., Silva, M.G., Fonseca, L. D. S., \& Lilenbaum, W. (2006). Evaluation of Mycobacterium avium subsp. Paratuberculosis faecal culture protocols and media. Pesquisa Veterinaria Brasileira, 26(1), 1-4.

Sechi, L. A., \& Dow, C. T. (2015). Mycobacterium avium ss. Paratuberculosis zoonosis-The Hundred Year War-beyond Crohn's disease. Frontiers in Immunology, 6, 96.

Sevilla, I., Garrido, J. M., Geijo, M., \& Juste, R. A. (2007). Pulsedfield gel electrophoresis profile homogeneity of Mycobacterium avium subsp. paratuberculosis isolates from cattle and heterogeneity of those from sheep and goats. BMC microbiology, 7, Article number 18.

Sevilla, I., Singh, S. V., Garrido, J. M., Aduriz, G., Rodriguez, S., \& Geijo, M. V. (2005). Molecular typing of Mycobacterium avium subspecies paratuberculosis strains from different hosts and regions. Revue Scientifique et Technique, 24(3), 10611066.

Singh, A. V., Chauhan, D. S., Singh, A., Singh, P. K., Sohal, J. S., \& Singh, S. V. (2015). Application of IS1311 locus 2PCRREAassay for the specific detection of 'Bison type' Mycobacterium avium subspecies paratuberculosis isolates of Indian origin. Indian Journal of Medical Research, 141(1), 5561.

Singh, S. V., Singh, P. K., Singh, A. V., Sohal, J. S., Gupta, V. K., \& Vihan, V. S. (2007). Comparative efficacy of an indigenous 'Inactivated vaccine' using highly pathogenic field strain of Mycobacterium avium subspecies paratuberculosis
'Bison type' with a commercial vaccine for the control of Capri - Paratuberculosis in India. Vaccine, 25(41), 7102-7110.

Singh, S. V., Sohal, J. S., Singh, P. K., \& Singh, A. V. (2009). Genotype profiles of Mycobacterium avium subspecies paratuberculosis isolates recovered from animals, commercial milk and human beings in North India. International Journal of Infectious Diseases, 13(5), 221-227.

Singh, S., Dhakal, I. P., Singh, U. M., \& Devkota, B. (2020). Detection of Mycobacterium avium sub sp.paratuberculosis (MAP)by PCR in the faeces of dairy cattle of Chitwan, Nepal. Journal of Agriculture and Forestry University, 4, 217-224.

Singh, S., Dhakal, I. P., Singh, U. M., \& Devkota, B. N. (2018). Current diagnostic techniques of Mycobacterium avium subsp. paratuberculosis in domestic ruminants. Journal of Agriculture and Forestry University, 2, 23-34.

Sivakumar, P., Tripathi, B. N., \& Singh, N. (2005). Detection of Mycobacterium avium subsp. paratuberculosis in intestinal and lymph node tissues of water buffaloes (Bubalus bubalis) by PCR and bacterial culture. Veterinary Microbiology, 108(3-4), 263-270.

Sohal, J. S., Singh, S. V., Singh, P. K., \& Singh, A. V. (2010). On the evolution of 'Indian Bison type' Mycobacterium avium sub species paratuberculosis. Microbiology Research, 165, 163171.

Sohal, J. S., Singh, S. V., Singh, P. K., Singh, A. V., \& Kumar, N. (2013). A new marker IS1311L2 PCR-REA for identification of 'Indian Bison Type' Mycobacterium avium subspecies paratuberculosis. Indian Journal of Biotechnology, 12, 204207.

Sonawane, G. G., Narnaware, S. D., \& Tripathi, B. N. (2015). Molecular epidemiology of Mycobacterium avium subspecies paratuberculosisin ruminants in different parts of India. International Journal of Mycobacteriology, 5(1), 59-65.

Stabel, J. R. (1997). An improved method for cultivation of Mycobacterium paratuberculosis from bovine fecal samples and comparison to three other methods. Journal of Veterinary Diagnostic Investigation, 9(4), 375-380.

Thibault, V. C., Bryant, J., Harris, S., Bentley, S., Smith, D. G. E., McLuckie, J., Parkhill, J., \& Stevenson, K. (2012). Genome sequencing to identify phylogenetic diversity and single nucleotide polymorphisms in Mycobacterium avium subsp. paratuberculosis. Proceedings of the Eleventh International Colloquium on Paratuberculosis, p. 267.

van Soolingen, D., de Haas, P. E. W. E., Hermans, P. W. M., Groenen, P. M. A., \& van Embden, J. D. A. (1993). Comparison of various repetitive DNA elements as genetic markers for strain differentiation and epidemiology of Mycobacterium tuberculosis. Journal of Clinical Microbiology, 31(8), 19871995.

Whittington, R. J., \& Sergeant, E. S. (2001). Progress towards understanding the spread, detection and control of Mycobacterium avium subsp. paratuberculosis in animal populations. Australian Veterinary Journal, 79(4), 267-278.

Yue, R., Liu, C., Barrow, P., Liu, F., Cui, Y., Yang, L., Zhao, D., \& Zhou, X. (2016). The isolation and molecular characterization of Mycobacterium avium subsp. paratuberculosis in Shandong Province, China. Gut Pathogens, 8, Article number 9. 